\title{
Plant Digestive Supplement Designed by Lactobacillus Regulated Leukocyte Subsets through Activation of Complement Components and Implication for Use against Tumor Bearing Host against Infection
}

\author{
Kohji Ohtubo1, Nobuo Yamaguchi1,2*, Nurmuhamamt Amat ${ }^{3}$, Dilxat Yimit ${ }^{3}$, Parida Hoxur ${ }^{4}$ \\ Hiroshi Ushijima ${ }^{2}$ and Yousuke Watanabe ${ }^{2}$ \\ ${ }^{1}$ Ishikawa Natural Medicinal Products Research Center, Ishikawa, Japan \\ ${ }^{2}$ Department of Fundament Research for CAM, Kanazawa Medical University, Ishikawa, Japan \\ ${ }^{3}$ Traditional Uighur Medicine Department, Xinjiang Medical University, Urumqi, China \\ ${ }^{4}$ Traditional Chinese Medicine Hospital, Xinjiang Medical University, Urumqi, China \\ Email: serumaya@kanazawa-med.ac.jp
}

Received 14 May 2015; accepted 28 August 2015; published 31 August 2015

Copyright (C) 2015 by authors and Scientific Research Publishing Inc.

This work is licensed under the Creative Commons Attribution International License (CC BY).

http://creativecommons.org/licenses/by/4.0/

(c) () Open Access

\begin{abstract}
A plant material consisted by Family Poaceae was fermented by Yeast and Lactobaccilli (U-164). This material was proved by as safe in animal safety experiment for oral administration. In order to prove the effect of U-164 against physiological function, the animal and human trials were set up to look into mainly leukocyte functions. In animal experiment, anti-oxidative effect and antibody response in immune-compromised host and diabetes meritus were made up. For human use, peripheral lymphocyte in number and subset ratio were followed up to one month after administration. In order to understand its effect, human complement component analysis was made by immune-electrophoresis. Our results showed that U-164 augmented the level of lymphocytes, while U-164 down regulated the level of granulocytes. In our clinical study with 19 healthy volunteers, granulocyte and lymphocyte ratio was obtained as neutral in peripheral blood being increased significantly 30 days after the ingestion of $U$-164. In experimental animal study, the compromised host as well as normal animal was administered with cancer chemotherapeutic agent (Mytomycin-C). Our observations showed against antibody producing cell, this material recovered the antibody production in the host compromising the immure responsiveness. We also proposed an idea that U-164 exhibited tonic effects via activating complement components. Moreover, we tried to access further to the anti-oxidative activities of this U-164. This modification brought to "Corresponding author.
\end{abstract}

How to cite this paper: Ohtubo, K., et al. (2015) Plant Digestive Supplement Designed by Lactobacillus Regulated Leukocyte Subsets through Activation of Complement Components and Implication for Use against Tumor Bearing Host against Infection. Open Journal of Immunology, 5, 133-146. http://dx.doi.org/10.4236/oji.2015.53013 
the significant lifted up for anti-oxidative activity for phagocytic cell.

\author{
Keywords
}

Family Poaceae, Fermentation, Yeast, Lactobacillus, Cancer Chemotherapeutic Agent,
Compromised Host, Complement, C3b Fragment, Anti-Oxidant, Diabetes, Blood Sugar

\title{
1. Introduction
}

In recent years, complementary and alternative medicines (CAM) have achieved more and more attentions since they are able to treat many chronic illnesses, such as fatigue syndrome that plagues the industrialized world. The present team has reported that typical styles of CAM, preparing special molecule for both digestive and easy to activated human complement component regulate functions of leukocytes in human immune system [1] [2]. Dietary and fermented formula holds promise as strong inducers of acquired immunity. While the immune system is working against the local infection of pathogens, cytokine and immuno-competent cells react throughout the body in close connection to the brain, the endocrine and immune system [3]. In this study, we hypothesize that U-164 may influence immuno-competent cells qualitatively and quantitatively U-164 targeting lymphocytes based on the constitution dependent manner. U-164 has been employed as tonic agent and the implication has little been made on the characteristics of the levels of leukocyte subset, such as granulocytes and lymphocytes. In this report, we seek to focus on the identity of U-164 formula, comparing to another herbal medicine. The influence of U-164 on leukocyte and/or lymphocyte subpopulations in human peripheral blood is also discussed. Moreover, some preliminary trials for the new processing of herbal formulae by degradation of acidophilic bacteria and yeast fungus [4].

\section{Materials and Methods}

\subsection{Animal Study}

\subsubsection{Single and Multiple Dose Toxicity Study}

Nine female seven-week-old ddY mice, were used for the acute oral toxicity study. The tests were carried out according to Ethics of the Organization for Economic Co-operation and Development (OECD) Test Guideline 401. The mice were housed at $24^{\circ} \mathrm{C} \pm 1^{\circ} \mathrm{C}, 50 \%$ relative humidity. Both conventional and charged water were suspended in sterile and administered to mice in free supplemental system, calculating daily consumption. Mice were weighted at 0 - 7 days after administration, and clinical observations were made once a day. Necropsy was performed on all mice seven days after administration.

\subsubsection{Schematic Diagram for Bone Marrow Suppressed Immune-Compromised Mice}

In the animal model of immuno-competency reduction, male C57BL/6J mice, aged 8 - 9 weeks, were injected with Mitomycin-C (MMC) (5 mg/kg) to inhibit the bone marrow. Then, U-164 extracts was administered orally at a dosage of $1 \mathrm{~g} / \mathrm{kg} /$ day for five consecutive days. Normal animals were chosen as controls [5] (Figure 1).

\subsection{Preparation of $\mathrm{U}-164$}

U-164 was prepared using method of Ohtubo, et al. A plant material, sugarcane, consisted by Family Poaceae were fermented by Yeast and Lactobaccilli (U-164). After the incaution for five years, liquid materials were served for U-164 (COSMOS Co. Ltd. Kurume, Fukuoka, Japan).

\subsection{Recovery of Immuno-Competence}

\subsubsection{Recovery off White Blood Cells by U-164}

The bone marrow-suppressed mice were administered herbal decoction U-164 $1 \mathrm{~g} / \mathrm{kg}$ dairy for 5 days and after 1 week later, their blood were withdrawn from their tail vain. Then, the number of leukocytes was counted in Bürker-Türk solution. 


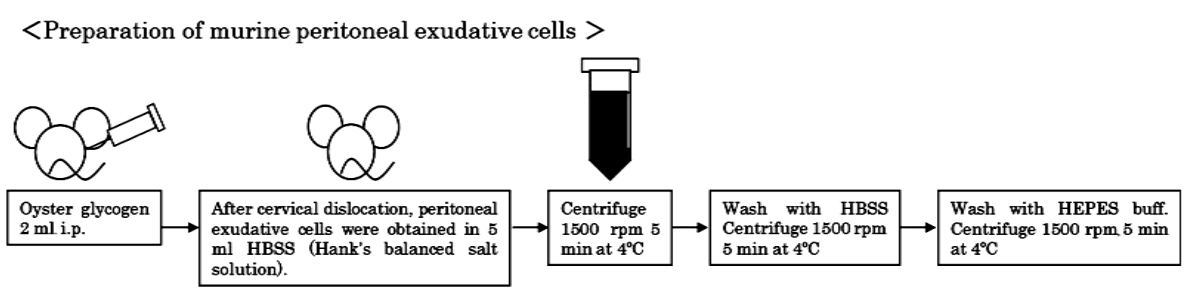

$<$ Measurement of generated super oxide >

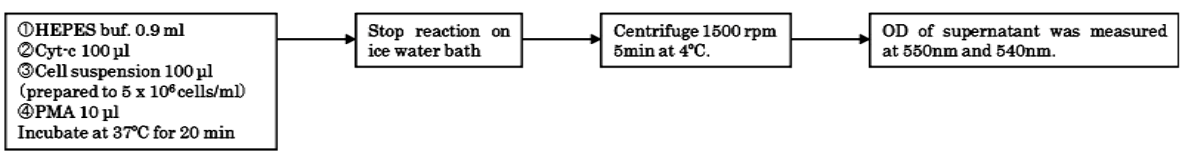

Figure 1. Experimental design for this report. The bone marrow suppressed mice were administered fermented decoction of U-164 (1 g/kg/day) for 5 days. One week later, mice were immunized with sheep red blood cells, $\left(2 \times 10^{8}\right.$ /mouse) intraperitoneally. Five days later, their spleen cells were collected. Plague-forming cells (PFC) were developed, and the ability of IgM and IgG antibody production was tested U-164 by the method reported in the text.

\subsubsection{Regulatory Effect of Leukocyte Subsets}

Bone marrow-suppressed mice were administered with herbal decoction of U-164 (1000 mg/kg) for 10 days. One week later, the blood from their tail vain was withdrawn. Then the granulocyte and lymphocyte subsets were counted in Bürker-Türk solution.

\subsubsection{Recovery of Macrophage Activity, Migration}

Cells from peritoneal exudates were collect from the peritoneal cavity of bone marrow-suppressed mice. Phagocytes were purified using adherent technique to get cell suspensions which contained more than $95 \%$ of phagocytes. The purified cells were loaded to the upper room of Boyden chamber to test migration ability at a concentration of $1 \times 10^{4} \mathrm{cell} / \mathrm{ml}$. Human serum treated at $56^{\circ} \mathrm{C}$ for $30 \mathrm{~min}$ was for the chemo tactic agent of mouse phagocyte [6].

\subsubsection{Recovery of Macrophage Activity, Phagocytosis}

The same cells suspension was purified by adherent technique for phagocyte, which produces cells contained more than $95 \%$ of phagocytes. The purified cells were adjusted to $1 \times 10^{4} \mathrm{cell} / \mathrm{cm}^{2}$ and mixed with latex beads that are 5um in granule wit U-164 luorescence isochianate. After $90 \mathrm{~min}$ of incubation, remained granule were washed out from the glass slide. Number of phagocytic cell and their ability to catch up the latex beads were automatically measured by ACAS system, which outputs the result in a digital form (Adherent cell activity evaluating system; Shimazu, Kyoto, Japan).

\subsubsection{Augmentation of Lymphocyte Activity, Antibody Secreting Cell}

The bone marrow suppressed mice were administered herbal decoction of U-164 (1 g/kg/day) for 5 days. One week later, mice were immunized with sheep red blood cells, $\left(2 \times 10^{8} /\right.$ mouse $)$ intraperitoneally. Five days later, their spleen cells were collected. Plague-forming cells (PFC) were developed, and the ability of IgM and IgG antibody production was tested U-164he method reported by Jerne and Nordin [7] [8].

\subsubsection{Effect for CD Positive Lymphocyte Distribution by U-164 against Different Constitution}

Whole blood obtained from the subjects was washed twice with PBS. One hundred micro-liters of the suspensions were stained with $20 \mu \mathrm{l}$ of fluorescent monoclonal antibodies (anti-human $\mathrm{CD} 2^{+}, \mathrm{CD} 4^{+}, \mathrm{CD} 8^{+}, \mathrm{CD} 11 \mathrm{~b}^{+}$, $\mathrm{CD}_{14}^{+}, \mathrm{CD} 6^{+}, \mathrm{CD}_{19}{ }^{+}$and $\mathrm{CD}_{5}{ }^{+}$antibodies). Ten thousands stained cells were re-suspended in PBS to detect surface markers by flow cytometry (FACS Calibur; Becton Dickinson Immnocytometry Systems, CA, USA).

\subsubsection{Recovery of Cytokine Producing Lymphocytes in Different Constitution}

The blood cell suspensions were cultured with PMA (phorbol 12-myristate 13-acetate), ionomycin and BSA 
(bovine serum albumin) for $4-5$ hours at $37^{\circ} \mathrm{C}$. After that, the cell suspensions were stained using the monoclonal antibodies of PE-IL-4, FITC-IFN- $\gamma$ and FITC-IL-1 $\beta$. Then they were analyzed U-164he FACScan (Becton Dickinson Co. Ltd. USA). The antibodies and reagents used in the test were purchased from Becton Dickinson Immunocytometry System (USA).

\subsubsection{Evaluation of Macrophage Activity, Phagocytosis}

The peritoneal exudates cells were collect from the peritoneal cavity of bone marrow-suppressed mice. Cell suspensions were purified by adherent technique for phagocyte, getting a suspension which contained over $95 \%$ of phagocytes. The purified cells were adjusted to $1 \times 10^{4} \mathrm{cell} / \mathrm{ml}$ and loaded at the upper chamber of Boyden chamber for test migration. Human serum with treated at $56^{\circ} \mathrm{C}$ for 30 min was for the chemotactic agent for mouse phagocyte.

Phagocytic activity and antibody production of macrophages were analyzed using a classical test that could test the total activity of the immune system by examine chemotaxis, phagocytosis and intracellular degradation of macrophage. For identifying antibody-forming cells, plaque-forming cells were detected using heterogeneous erythrocyte; sheep erythrocyte was a target antigen. Peritoneal macrophages were collected and purified in fetal calf serum (FCS)-coated petri-dishes. The cell population was approximately $97 \%$ uniform in function and morphology. These cells were applied to the nuclepore-membrane (pore size: $5 \mu \mathrm{m}$; Neuro Probe Co. Ltd., Cabin John MD, USA) with a chemotaxis chamber (Neuro Probe Co. Ltd.). After 90 minutes' incubation, the membrane was vigorously washed with saline $\left(37^{\circ} \mathrm{C}\right)$, fixed, and then stained with methylene blue dye. After counting under a microscope for the total field of the membrane, the average number of migrating cells was expressed as cell counts/mm².

The same cells suspension was purified by adherent technique for phagocyte, which contained over $95 \%$ of phagocytes. The purified cells were adjusted to $1 \times 10^{4} \mathrm{cell} / \mathrm{cm}^{2}$ and mixed with latex beads that were $5 \mathrm{um}$ in granule wit U-164 luorescence isochianate. After 90 min of incubation, the remained granule were washed out from the glass slide and counting automatically by ACAS system, which outputs digital presentation, for evaluating phagocytes in number and in their ability to catch up the latex beads (ACAS: adeherent cell activity analyzing system, Shimazu, Kyoto, Japan). Latex beads in $5 \mu \mathrm{m}$ with fluorescence were used to test phagocytic activity and Candida albicans was cell killing activity. A macrophage-target cell ratio of 1:10 was considered to be optimum. Ten minutes after incubating phagocytes and target cells, intracellular Candida cells were cultured on an agar dish with conventional medium 1640 until the next day to perform the colony forming assay. In this way, the phagocytic ability of the macrophages was monitored. To document intracellular killing activity, the same procedures were performed excepting that the incubation time was changed to 90 minutes.

\subsubsection{Antibody Forming Cell Study by U-164}

Sheep erythrocyte (SRBC), a T-dependent antigen, was used for antibody formation cell study. Ten days after tumor transplantation, each antigen was intra-peritoneally injected. After four and six days, the antibody-forming cells were detected using localized hemolysis in an agar gel. Plaque-forming cells were developed U-164he method of Jerne and Nordin [7] [8].

\subsection{Anti-Oxidative Evaluation of U-164 by Phagocytic Cell}

\subsubsection{Animals for This Test}

Eight week-old female C57BL/6 were purchased from Sankyo Laboratory Service Corporation (Shizuoka, Japan). All mice were kept under specific pathogen-free conditions. Mice food and distilled water were freely accessible for each mouse. Housing temperature and humidity were controlled $25^{\circ} \mathrm{C} \pm 1{ }^{\circ} \mathrm{C}$ and $60 \%$.

\subsubsection{Reagents for This Measurment}

As for the basic medium, HEPES buffer (HEPES $17 \mathrm{mM}, \mathrm{NaCl} 120 \mathrm{mM}$, Glucose $5 \mathrm{mM}, \mathrm{KCl} 5 \mathrm{mM}, \mathrm{CaCl}_{2} 1 \mathrm{mM}$, $\mathrm{MgCl}_{2} 1 \mathrm{mM}$ ) was prepared and sterilized by filtration. Phorbol 12-myristate 13-acetate (PMA, Sigma, USA) was diluted to $10^{-6} \mathrm{M}$ by dimethyl sulfoxide DMSO, Sigma, USA) and used as a stimulant for super oxide anion generation for murine peritoneal exudates cells. Cytochrome-c (Sigma, USA) was diluted to 1mM by HEPES buffer. Since cytochrome-c reduced by super oxide showed maximum absorbance at $550 \mathrm{~nm}$, we used cytochrome-c to measure the amount of super oxide anion generation through spectro-photometrical technique. Oyster 
glycogen (type II, Sigma, USA) was diluted in the purified water (10\% w/v, Wako, Japan) and autoclaved at $120 \mathrm{C}$ for $20 \mathrm{~min}$. This solution was used for intraperitoneal injection to mice in order to induce peripheral neutrophils into the abdominal cavity.

2.4.3. Estimating the Amount of Super Oxide Anion Generated by Murine Peritoneal Exudates Cells Each remedy was orally administered to mice $(500 \mathrm{mg} / \mathrm{kg}$ ) for one week. Two milliliters of $10 \%$ Oyster glycogen was injected intraperitoneally 10 hours before the assay. Sufficient murine peritoneal exudative cells were induced ten hours after the stimulation. Mice were euthanized by cervical dislocation, murine peritoneal exudates cells (PEC) suspension was centrifuged twice for 5 minutes at $1500 \mathrm{rpm}$ at $4^{\circ} \mathrm{C}$. Then PEC was prepared to $1 \times 10^{6}$ cells/ml of HEPES buffer. One hundred microliters of cytochrome-c and $10 \mu \mathrm{l}$ of PMA were added to the cell suspension and this was incubated for 20 minutes at $37^{\circ} \mathrm{C}$. The reaction mixture was then centrifuged for 10 minutes at $1500 \mathrm{rpm}, 4^{\circ} \mathrm{C}$. An OD of supernatant was measured at both $550 \mathrm{~nm}$ and $540 \mathrm{~nm}$, the amount of generated super oxide anion was shown in the formula; increased absorbance at $550 \mathrm{~nm}\left(\Delta \mathrm{A}_{50-540}\right) / 19.1 \times 10^{3}$ $(\mathrm{mmol} / \mathrm{ml})$. In order to ensure if we really measured the amount of generated super oxide anion or not, we tried to add super oxide anion dismutase (SOD), an enzyme for its anti-oxidative effect, into our experimental system. The result was as expected that the reduction of cytochrome-c was inhibited after the addition of SOD. This showed us that our experimental system could be used properly for measuring the amount of generated super oxide anion.

\subsection{Statistical Analysis}

Data are expressed as means \pm standard deviations. The differences between U-164-treated and non-treated conditions were compared using a one-tailed analysis of variance. A $P$ value $<0.05$ was considered to be statistically significant.

\section{Clinical Findings by U-164}

\subsection{Volunteers and Assessing QOL for U-164}

Twenty healthy volunteers aged from 21 to 70 years for both sex were recruited and were administered U-164 for 30 days. Fifteen milliliters of blood were drawn from the forearm vein one hour before the first administration of U-164 and 30 days after the last U-164 administration (day 30). All volunteers provided informed consent prior to participation for this trial. This study was approved by Ethics Committee of Kanazawa Medical University.

\subsection{Leukocyte Counts Test for U-164}

The assessments including a total number of leukocytes was ordered to count with blood chemical test for the medical diagnosis of public institution (Ishikawa Preventive Medicine Association, Ishikawa, Japan). In the differential counting, 200 cells were counted on a May-Grünewald-Gimsa stained slide, and percentages of lymphocytes and granulocytes were determined.

\subsection{Leukocyte Subset Analyses for U-164}

The assessments including a total number of leukocytes was ordered to count with blood chemical test for the medical diagnosis of public institution (Ishikawa Preventive Medicine Association, Ishikawa, Japan). In the differential counting, 200 cells were counted on a May-Grunewald-Gimsa stained slide, and percentages of lymphocytes and granulocytes were determined [8].

\section{Results for U-164}

\subsection{Animal Experiment}

\subsubsection{One Shot and Multiple Shots Toxicity Study of Conventional Sugarcane and Fermented Sugarcane (U-164)}

No deaths or abnormalities of body weight, water and food consumption, or coat condition were observed in the 
treated mice. Necropsy evaluation of the mice did not reveal any significant differences in thymus, liver, spleen, kidney, adrenal gland and testicle weights between the control group and both conventional sugarcane and fermented sugarcane groups, or between males and females.

\subsubsection{Recovery of Whole Body Weight by U-164}

The body weight and thymus weight reduced in bone marrow-suppressed mice, resulting in the reduction of peripheral blood leukocyte to around 40\%. After administered each herbal decoction $1 \mathrm{~g} / \mathrm{kg}$ dairy for 5 days and after 1 week later, their blood were recovered to around 90\% of normal value (Figure 2).

\subsubsection{Recovery of Thymus Weight by $U-164$}

The bone marrow-suppressed mice were administered U-164 $1 \mathrm{~g} / \mathrm{kg}$ dairy for 5 days, and one week later, their blood was withdrawn from their tail vein. The cell count of the peripheral blood is showed in Figure 4, Table 1. shows that the thymus weight decreased to half of normal control after $5 \mathrm{mg} / \mathrm{kg}$ of MMC was injected. However, all the three U-164s recovered thymus weight to about $70 \%$ of the control.

\subsubsection{Augmentation of $\mathrm{CD}^{+}$Cells and Cytokine Producing Cells by U-164}

CD3, CD4 and CD19 cells of MMC treated mice were recovered to almost normal values after the administration of U-164s. As for the functional recovery, IFN- $\gamma$ and IL-4 producing cells were also recovered U- 164 . The all three decoction, including U-164 and a functionally depressive agent of TCM. In cytokine producing cells, IFN-r and IL-4 producing cell were recovered with U-164. In all these sugarcanes derivatives tested, cytokine producing cells were recovered with U-164 was the most and even conventional sugarcane formulae.

\subsubsection{Sorting Subjects into Two Groups, G-Type and L-Type by Granulocyte and Lymphocyte Proportion by U-164}

The volunteers were healthy subject, with no drastic change for the total number of leukocytes. However, we tried to check the regulative effect of herbal formulae for two different constitution, G-rich type and L-rich type. Analysis that mixed both groups together showed no significant differences in total leukocyte number except that for FBT; in G-type group, total number of leukocytes was down regulated by BT derivatives. This was a results of the down regulation of major group of leukocyte, granulocyte.

As for the L-type, no significant changes were found after the treatment of both FBTs. In the L-type group, on the other hand, increased the tonal leukocyte and granulocyte in number, on the contrary to the down regulation for lymphocytes. To further clarify the influence of hemopoietic formula, we divided the subjects into two groups: the G-type group, who had a granulocyte count over $60 \%$, and the L-type group, who had a lymphocyte count over $40 \%$. In the L-type group, lymphocyte counts tended to decrease on day 10 , accompanied by an increase in granulocyte numbers by U-164 but not by conventional sugarcane. On the contrary, the granulocyte counts of G-type group tended to decrease on day 10. The decrease of granulocyte count was raised by U-163, but not by conventional sugarcane on day 10 (Table 2, Table 3).
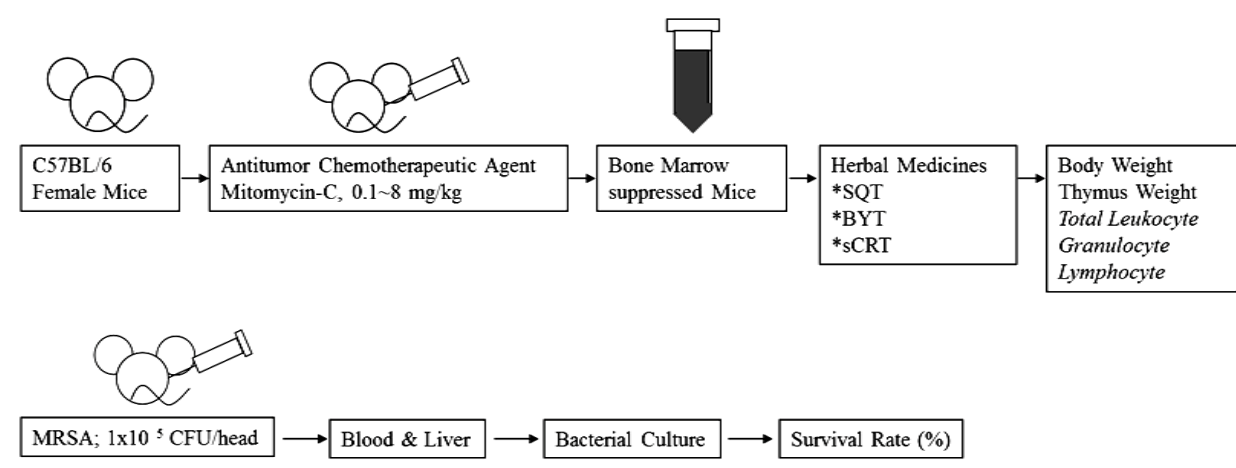

Figure 2. Twenty-four hours change of total peripheral leukocyte count on the basis of each constitution/condition. We tried to express the effect of peripheral total leukocyte number by individual level of change and plot in the $\mathrm{x}$-axis as in each age. Variations in leukocyte subpopulations in the peripheral blood before and after U-164 therapy. 
4.1.6. Augmentation of Lymphocyte Activity, Antibody Secreting Cell

The bone marrow-suppressed mice were administered herbal decoction U-164 for five days. One week later,

Table 1. Constitution Dependent Regulation of Leukocyte Subset by U-164.

\begin{tabular}{ccccc} 
& \multicolumn{2}{c}{ G-type individual } & \multicolumn{2}{c}{ L-type individual } \\
\hline & \multicolumn{2}{c}{ Original Sugarcane } & \multicolumn{2}{c}{ Fermented Sugarcane } \\
\hline & Before & After & Before & After \\
\hline Total WBC $\left(\times 10^{3} \mu \mathrm{l}\right)$ & 6.56 & 5.78 & 4.97 & 6.88 \\
Lymphocyte (\%) & 25.8 & 27.6 & 45.8 & 47.2 \\
Granulocyte (\%) & 69.7 & 69.7 & 60.2 & 65.6 \\
Neutrophil (\%) & 65.8 & 62.4 & 49.6 & 3.4 \\
Eosinophil (\%) & 2.9 & 2.5 & 2.4 & 0.8 \\
\hline Basophil (\%) & 0.6 & 0.7 & 0.8 & 3.9 \\
\hline
\end{tabular}

Table 2. Constitution dependent regulation of leukocyte by U-164.

\begin{tabular}{|ccccc}
\hline & \multicolumn{2}{c}{ G-type individual } & \multicolumn{2}{c}{ L-type individual } \\
\hline & \multicolumn{2}{c}{ Original Sugarcane } & \multicolumn{2}{c}{ Fermented Sugarcane } \\
\hline & Before & After & Before & After \\
\hline Total WBC $\left(\times 10^{3} \mu 1\right)$ & 6.11 & 5.98 & 5.62 & 6.88 \\
Lymphocyte (\%) & 24.7 & 26.8 & 41.3 & 44.5 \\
Granulocyte (\%) & 66.6 & 67.6 & 52.6 & 58.9 \\
Neutrophil (\%) & 63.5 & 62.6 & 51.0 & 53.2 \\
Eosinophil (\%) & 1.5 & 2.1 & 2.3 & 3.8 \\
Basophil (\%) & 0.5 & 0.9 & 0.6 & 0.8 \\
\hline
\end{tabular}

Table 3. Constitution dependent regulation of lymphocyte by Sugarcane Derivatives.

\begin{tabular}{|c|c|c|c|c|}
\hline \multirow{3}{*}{ CD } & \multicolumn{2}{|c|}{ G-type individual } & \multicolumn{2}{|c|}{ L-type individual } \\
\hline & \multicolumn{2}{|c|}{ Original Sugarcane } & \multicolumn{2}{|c|}{ Fermented Sugarcane } \\
\hline & Before (\%) & After (\%) & Before (\%) & After (\%) \\
\hline CD2 & 61.45 & 73.34 & 62.46 & 71.46 \\
\hline CD4 & 18.44 & 29.78 & 33.43 & 47.66 \\
\hline CD8 & 37.56 & 42.54 & 29.69 & 28673 \\
\hline CD11 & 73.56 & 73.56 & 65.63 & 73.74 \\
\hline CD14 & 0.05 & 0.05 & 0.06 & 0.07 \\
\hline CD16 & 65.79 & 57.35 & 55.54 & 47.54 \\
\hline CD19 & 8.67 & 8.46 & 8.21 & 7.99 \\
\hline CD56 & 1.03 & 1.96 & 2.06 & 2.75 \\
\hline
\end{tabular}


mice were immunized with sheep red blood cells, $\left(2 \times 10^{8} /\right.$ mouse $)$ intraperitoneally. Four and six days later, their plague-forming cells (PFC) were developed. The ability of IgM and IgG antibody production was tested U164 he method reported by Jerne and Nordin [7]. In this mouse model, MMC did not reduce the antibody forming cells significantly but the tendency was the same as shown in the former section. In this test, B was the most effective than that of A. U-164 was the strongest material to augment antibody secreting cell among the four formulae.

\subsubsection{Macrophage Phagocytic Activity by U-164}

So as to detect the supportive effect and important immunological stimulation U-164onic agent, Bu-Ji, we traced the augmentation pattern of each remedy. As results of this trial, the phagocytic patterns U-164onic agents, Bu$\mathrm{Ji}$, were clearly different from MMC-treated mice. Moreover, augmentation of phagocytes were different between each sugarcane derivatives. U-164 was prominent in activating phagocytes quantitatively and qualitatively compared to conventional sugarcane. We showed the diversity in the recovery pattern of U-164. Famous tonic remedies in Japan, U-164, strongly recovered phagocytic activity in compromised hosts, but the recovery by fermented sugarecane/U-164 was much less than that by original sugarcane (Table 4).

\subsection{The Level of Generated Super Oxide Anion Controlled by U-164}

The amount of generated super oxide anion was calculated in the formula shown above. The generated super oxide anion after one week administration of Agaricus and Chlorella were 2.64 and $1.95 \times 10^{-5} \mathrm{mmol} / \mathrm{ml}$, respecttively, whereas that was $2.85 \times 10^{-5} \mathrm{mmol} / \mathrm{ml}$ in control group. The generated super oxide anion after one week administration of conventional turmeric, fermented formulae, were $1.24,1.25$ and $2.88 \times 10^{-5} \mathrm{mmol} / \mathrm{ml}$, respectively. The generated super oxide anion after one week administration of Propolis was $2.55 \times 10^{-5} \mathrm{mmol} /$ $\mathrm{ml}$. All these drugs, except for U-164, decreased super oxide anion generation after administration for one week in mice.

\section{The Estimation of Generated Super Oxide Anion between the Fermented and Not Fermented Sugarcane/U-164}

Since the antioxidative effects of herbal medicine were demonstrated, we investigated the way to reinforce this effect. The fermentation is one of the possibilities. Since the fermentation is preceded by bacterial digestion and degradation, less efficient constituents would be lost than commonly used extraction by hot water. Therefore, we decided to ferment the herbal medicine by yeast (Saccharomyces cerevisiae), expecting the enhancement of its antioxidative effects. The generated super oxide anion after one week administration of fermented U-164. All the fermented herbal medicine decreased super oxide anion generation in compare with their corresponding unfermented ones (Table 5).

\section{Clinical Findings}

\subsection{Regulation in Cell Number of Total Leukocyte and Subsets}

Leukocyte numbers have been counted one hour before and 15 days after the treatment of hemopoitic formula.

Table 4. Relative activities of macrophage phagocytosis.

\begin{tabular}{|c|c|c|}
\hline & \multicolumn{2}{|c|}{ Phagocytosis } \\
\hline & \multicolumn{2}{|c|}{ Positive Cells $/ 10^{6}$ cells } \\
\hline & Law active (\%) & High active (\%) \\
\hline Normal & $52(100)$ & 45 (100) \\
\hline MMC & $34(65)$ & $5(11)$ \\
\hline MMC + C. Sugarcane & 108 (207) & 59 (131) \\
\hline MMC + F. Sugarcane & $187(326)$ & 89 (199) \\
\hline
\end{tabular}


Table 5. Anti-oxidative Activity of Peritoneal Macrophages treated by U-164.

\begin{tabular}{|c|c|}
\hline Materials & Generated $\mathrm{O}_{2}^{-}\left(\times 10^{5} \mathrm{mmol} / \mathrm{ml}\right)$ \\
\hline Agaricus burazei & 2.79 \\
\hline Conv. Sugarcane & 1.94 \\
\hline F. Sugarcane/U-164 & 1.63 \\
\hline Propolis & 2.55 \\
\hline Control & 2.99 \\
\hline
\end{tabular}

The cell number measured one hour before the administration was set as $100 \%$. Relative percentage of cell number on the 15th day was calculated. No significant changes were observed in G-group after the administration of U-164. However, significant change was found in L-type group.

\subsection{Dividing Subjects into Two Groups, G-Type and L-Type by the Ratio to Granulocyte and Lymphocyte}

The volunteers were healthy subject, with no drastic change for the total number of leukocytes. However, we tried to check the regulative effect of herbal formulae for two different constitution, G-rich type and L-rich type. Analysis that mixed both groups together showed no significant differences in total leukocyte number except that for U-164; in G-type group, total number of leukocytes was down regulated by U-164. This was a results of the down regulation of major group of leukocyte, granulocyte.

As for the L-type, no significant changes were found after the treatment of both U-164. In the L-type group, on the other hand, increased the tonal leukocyte and granulocyte in number, on the contrary to the down regulation for lymphocytes. To further clarify the influence of hemopoietic formula, we divided the subjects into two groups: the G-type group, who had a granulocyte count over 60\%, and the L-type group, who had a lymphocytecount over $40 \%$. In the L type group, lymphocyte counts tended to decrease on day 15 , accompanied by an increase in granulocyte numbers by conventional sugarcane but not by U-164. On the contrary, the granulocyte counts of G-type group tended to decrease on day 15. The decrease of granulocyte count was raised by U-164, but not by conventional sugarcane on day 10 .

\subsection{Lymphocyte Subsets Reveal Significant Variation by U-164}

After U-164 treatment, cell counts of $\mathrm{CD}^{+}, \mathrm{CD}^{+}, \mathrm{CD}^{+}, \mathrm{CD} 11 \mathrm{~b}^{+}, \mathrm{CD} 16^{+}, \mathrm{CD} 19^{+}$and $\mathrm{CD} 56^{+}$were tested to evaluate variations in T cells, B cells, macrophages and NK cells. These values were measured one hour before hemopoietic formula and 15 days thereafter. Our results showed that CD2 and CD4 cells were increased by both U-164 and SQT. CD11b ${ }^{+}$and CD14 ${ }^{+}$cell counts, which are closely associated with macrophage activity, increased by U-164 in the L-type subjects. In particular, there was a remarkable increase in CD11 ${ }^{+}$cell number on day 15 . $\mathrm{T}$ cell subsets that are closely associated with activity of immature $\mathrm{T}$ cells, $\left(\mathrm{CD2} 2^{+}, \mathrm{CD}^{+}{ }^{+}\right.$and $\left.\mathrm{CD} 8^{+}\right)$, the $\mathrm{CD}^{+}(P<0.05)$ showed an increase with the treatment of U-164 15 days after administration. The number of CD19+ cells, which is closely associated with B cell activity, was not changed by both U-164 throughout the trial, neither were the numbers of $\mathrm{CD}_{16}{ }^{+}$and $\mathrm{CD} 56^{+}$cells (Table 6).

\section{Products of Complement Activation Combining the Biological Activity}

Activation of either the alternative or the classical pathway results in the generation of many important peptides involved in inflammatory responses. The anaphylaxis increase of vascular permeability Degradation of mast cells and basophils with release of histamine Degradation of eosinophils Aggregation of platelets opsonization of particles and solubilization of immune complexes with subsequent facilitation of phagocytosis Release of neutrophils from bone marrow resulting in leukocytosis Smooth muscle contraction Increase of vascular permeability Smooth muscle contraction Increase of vascular permeability Degradation of mast cells and basophils with release of histamine Degradation Degranulation of eosinophils Aggregation of platelets Chemotaxis of basophils, eosinophils, neutrophils, and monocytes Release of hydrolytic enzymes from neutrophils Chemotaxis of neutrophils Release of hydrolytic enzymes from neutrophils Inhibition of migration and insulation of spreading 
Table 6. Constitution dependent regulation of $\mathrm{CD}^{+}$lymphocyte by U-164.

\begin{tabular}{|c|c|c|c|c|}
\hline \multirow{3}{*}{ CD } & \multicolumn{2}{|c|}{ G-type individual } & \multicolumn{2}{|c|}{ L-type individual } \\
\hline & \multicolumn{2}{|c|}{ Original Sugarcane } & \multicolumn{2}{|c|}{ Fermented Sugarcane } \\
\hline & Before (\%) & After (\%) & Before (\%) & After (\%) \\
\hline $\mathrm{CD} 2$ & 66.56 & 73.65 & 62.43 & 74.98 \\
\hline CD4 & 18.43 & 29.54 & 32.55 & 4532 \\
\hline CD8 & 34.33 & 43.45 & 27.66 & 26853 \\
\hline CD11 & 74.54 & 72.65 & 62.68 & 7253 \\
\hline CD14 & 0.03 & 0.06 & 0.07 & 0.07 \\
\hline CD16 & 65.54 & 55.87 & 57.43 & 46.73 \\
\hline CD19 & 8.65 & 8.21 & 8.36 & 8.54 \\
\hline CD56 & 1.30 & 1.87 & 1.93 & 2.47 \\
\hline
\end{tabular}

of monocytes and macrophages anaphylatoxins C3a, C4a, and C5a are derived from the enzymatic cleavage of C3, C4, and C5 respectively. Historically, C3a and C5a were defined as factors derived from activated serum possessing spasmogenic activity. The anaphylatoxins are now recognized as having many additional biologic functions. Both C3a and C5a are known to induce the release of histamine from mast cells and basophils (chapter 20A). As shown in Figure 4 both anaphylatoxins cause smooth muscle contraction and induce the release of vasoactive amines, which cause an increase in vascular permeability.

The effect of C5a anaphylatoxin on neutrophils is of considerable importance in the inflaammatory response. Not only can C5a induce neutrophil aggregation, but this anaphylatoxin appears to be the main chemotactic peptide generated by activation of either complement pathway. In vitro, nanomolar concentrations of C5a will induce the unidirectional movement of neutrophils. Other inflammatory cells, such as monocytes, eosinophils, basophils, and macrophages, have also been shown to exhibit a chemotactic response to C5a. The removal of the carboxy-terminal arginine from C5a by serum carboxy peptidase $\mathrm{N}$, generating C5a-des-arg, inactivates the spasmogen, yet restoration of full chemotactic activity of C5a-des-are may occur in the presence of serum. Therefore, C5a-desarg may also be responsible for in vivo neutrophil chemotactic activity.

As described earlier, the cleavage of C3 by either the alternative or the classical C3 convertases results in the production of two major split products, the C3a anaphylatoxin and cab. The larger C3b fragment can serve as an opsonin (promoter of phagocytosis) by binding to a target through the thioester mechanism. This renders the particle or cell immediately susceptible to ingestion by a variety of phagocytic cells that carry specific receptors for C3b.

Many recent observations point to additional roles for complement fragments in regulating the activity $9 \mathrm{f}$ cells of the immune system. These observations include the presence of receptors on lymphocytes for various complement proteins, including C3 split products and Factor $\mathrm{H}$, affecting B and T cell function. This is an important area for future research with this concept, we tried to demonstrate visually by the immune-electrophoresis. The human serum was prepared after administrating f-Black Turmeric together with the sample with before fermentation. Immuno-electrophoresis was setting up for 90 mins, followed by incubating with anti-human whole serum and specific for $\mathrm{C} 3$ and $\mathrm{Bf}$ component. These specifi anti complement component serum were kindly supplied by Dr Syunnosuke SAKAI, Cancer Research Institute of Kanazawa University, Japan (Figure 3, Figure 4).

\section{Discussion}

Our investigation clarified how U-164 influenced the immune system (e.g. leukocyte, granulocyte and lymphocyte subsets in particular). We quantified CD positive cell counts as indicators of T cells, B cells, macrophages and NK cells. For qualitative and quantitative evaluation, we examined the cytokine expression levels, and directly measured the expression levels of cytokine-containing cells in peripheral blood, eliminating possible artificial factors that could arise from culturing in test tubes or changes in net value by catalyzation. To avoid any possible influence from the circadian rhythm, we obtained the whole blood from all donors at the same time. In 


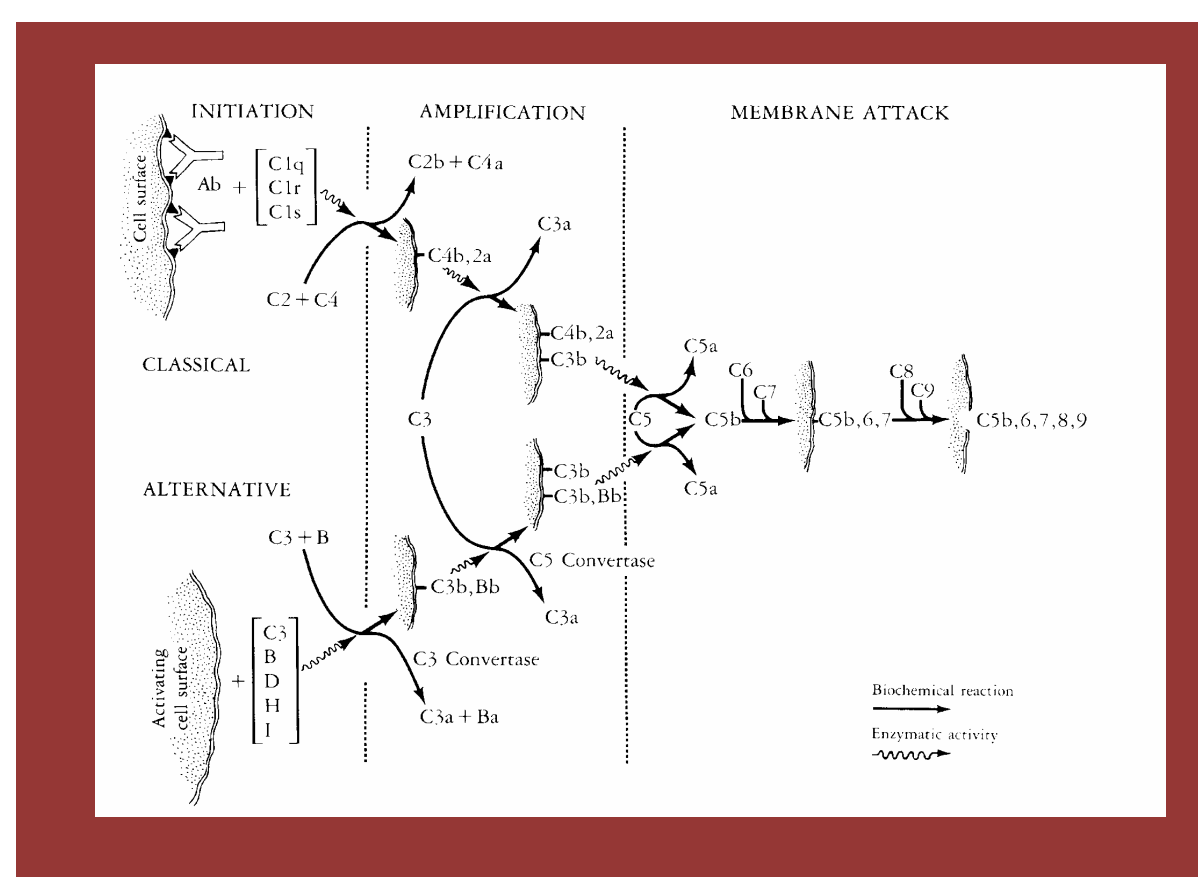

Figure 3. Diagrammatical representation of complement component in vertebrate. The analysis of CD positive cells by FCM was measured by gating in the lymphocytes region on the scattered gram. Figure shows an example analysis. Nonspecific reaction of the PE fluorescence was found in the isotype control.

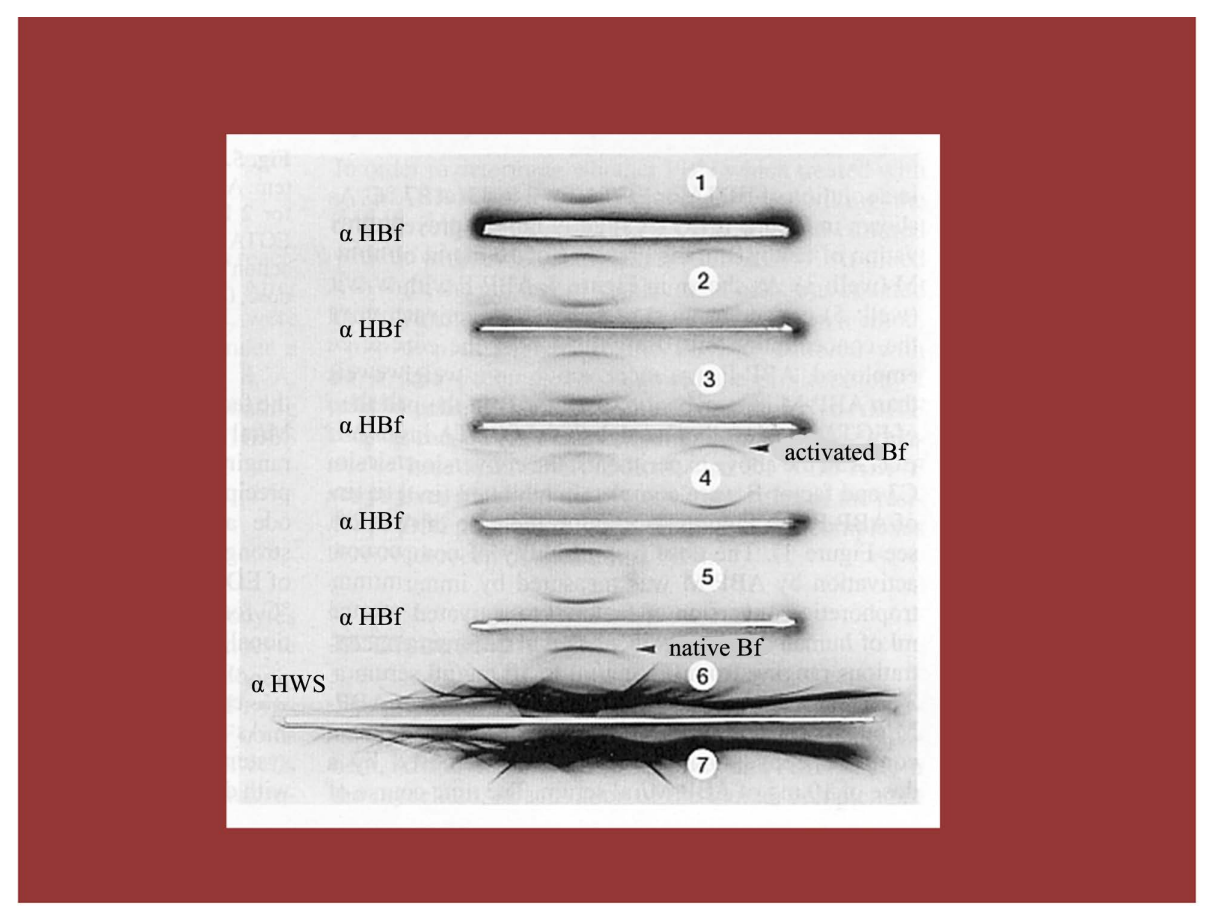

Figure 4. Immunoe; ectrophoretic demonstration of activated human Complement.

this investigation, we confirmed that U-164 quantitatively and qualitatively regulated leukocytes, granulocytes, lymphocytes and their subsets. The increase of $\mathrm{CD}_{2}^{+}, \mathrm{CD}^{+}, \mathrm{CD}^{+}, \mathrm{CD} 11 \mathrm{~b}^{+}, \mathrm{CD} 16^{+}, \mathrm{CD} 19^{+}$and $\mathrm{CD} 56^{+}$cell counts as well as the levels of IL- $1 \beta$, IL- 4 and IFN- $\gamma$ in blood cells suggested that hemopoitic formula might enhance the activities of humoral and cellular immunities, as well as NK cells. We also observed that levels of cy- 
tokine producing cells, in particular, increased rather than CD-positive lymphocytes, showing that U-164 augmented lymphocyte production qualitatively than quantitatively. Moreover, U-164 activated both CD11b cells and IL-1 $\beta$ producing cells, suggesting the activation of phagocyte cells both in number and in function. Consequently, these data further demonstrated that U-164 acted in macrophages in the same manner as Mycobacterium tuberculosis that had cell walls constructed of waxy substances [9]-[19].

In previous reports about hot-spring hydrotherapy and acupuncture, we had proposed that immune system regulation was an important factor for evaluating CAM. Since other substances, such as endotoxin and waxy substances from Mycobacterium tuberculosis, similar to proplis, were known for augmenting host immune responses. This time, we decided to focus solely on propolis. A possible explanation for immune enhancement could be the activation of the circular system and/or autonomic nervous system, although the details of the mechanism remained unclear. Further research regarding to the mechanism was necessary.

Abo et al. reported that granulocyte count was increased U-164he excitation of the sympathetic nervous system, while lymphocyte count was increased by excitation of parasympathetic nervous system [20]-[28]. Our data also showed that granulocyte count was decreased in subjects with a high granulocyte count, while lymphocyte count was increased in the same subjects. The lymphocyte count, however, was decreased in subjects with a high lymphocyte level, while granulocyte count was increased in the same subjects. In other words, the subjects dominated U-164he sympathetic nerve could release stress, whereas the sympathetic activity of subjects who were dominated U-164he parasympathetic nerve might be excited by hemopoietic formula. This way, the cell counts appeared to converge at appropriate levels after hemopoietic formula. Finally, in order to determine whether the elevation of leukocyte counts resulted from an infection triggered by hemopoitic formula or not, the subjects were followed up for 8 days after the last administration of hemopoitic formula. During that period, we could not observe any infectious signs such as pyodermitis, fever, or enhancement of C-reactive protein (CRP). The value of CRP was $0.57 \mathrm{~g} / \mathrm{dl}$ to $1.23 \mathrm{~g} / \mathrm{dl}$ in our subjects, suggesting very mild inflammatory responses, which showed that hemopoitic formula did not cause infection. Since the meridian may influenced cells through out the body and might pass through every organ system, hemopoitic formula stimulation might provide maximum benefits without dangerous side effects [28] [29]. As an immune-enhancer, fermented sugarcane, U-164 merits further investigation as a possible treatment for acquired immunodeficiency syndrome, chronic fatigue syndrome and other disorders that had been concerned throughout the world.

\section{Acknowledgements}

This project was partly supported by the Committee of Promotion of Acupuncture and Moxibustion Therapies in Japan.

\section{References}

[1] Kitada, Y., Wan, W., Matsui, K., Shimizu, S. and Yamaguchi, N. (2000) Regulation of Peripheral White Blood Cells in Numbers and Functions through Hot-Spring Bathing During a Short Term-Studies in Control Experiments. Journal of Japanese Society Balneology Climatology Physiological Medicine, 63, 151-164.

[2] Yamaguchi, N., Takahashi, T., Sugita, T., Ichikawa, K., Sakaihara, S., Tsugiyasu Kanda T., Arai, M. and Kawakita, K. (2007) Acupuncture Regulates Leukocyte Subpopulations in Human Peripheral Blood. Evidence-Based Complementary and Alternative medicine, 4, 447-453.

[3] Suzuki, S., Toyabe, S., Moroda, T., Tada, T., Tsukahara, A. and Iiai, T. (1997) Circadian Rhythm of Leukocytes and Lym-Phocytes Subsets and Its Possible Correlation with the Function of the Autonomic Nervous System. Clinical Experimental Immunology, 110, 500-508. http://dx.doi.org/10.1046/j.1365-2249.1997.4411460.x

[4] Yamaguchi, N., Kawada, N., Ja, X.-S., Okamoto, K., Okuzumi, K., Chen, R. and Takahashi, T. (2014) Overall Estimation of Anti-Oxidant Activity by Mammal Macrophage, Open Journal of Rheumatology and Autoimmune Diseases, 4, 13-21. http://dx.doi.org/10.4236/ojra.2014.41002

[5] Hamada, M. and Yamaguchi, N. (1988) Effect of Kanpo Medicine, Zyuzentaihoto, on the Immune Reactivity of Tumor-Bearing Mice. Journal of Ethnopharmacology, 24, 311-320. http://dx.doi.org/10.1016/0378-8741(88)90160-2

[6] Tu, C.C., Li, C.S., Liu, C.M. and Liu, C.C. (2011) Comparative Use of Biomedicine and Chinese Medicine in Taiwan: Using the NHI Research Database. Journal of Alternative and Complementary Medicine, 17, 339-346. http://dx.doi.org/10.1089/acm.2010.0200

[7] Jerne, N.K. and Nordin, A.A. (1963) Plaque Formation in Agar by Single Antibody Producing Cells. Science, 140, 405-408. http://dx.doi.org/10.1126/science.140.3565.405 
[8] Yamaguchi, N., Ueyama, T., Amat, N., Yimit, D., Hoxur, P., Sakamoto, D., Katoh, Y., Watanabe, I. and Su, S.-Y. (2015) Bi-Directional Regulation by Chinese Herbal Formulae to Host and Parasite for Multi-Drug Resistant Staphylococcus aureus in Humans and Rodents. Open Journal of Immunology, 4, 18-32. http://dx.doi.org/10.4236/oji.2015.51003

[9] Jong, M.S., Hwang, S.J., Chen, Y.C., Chen, T.J., Chen, F.J. and Chen, T.P. (2010) Prescriptions of Chinese Herbal Medicine for Constipation under the National Health Insurance in Taiwan. Journal of the Chinese Medical Association, 73, 375-383. http://dx.doi.org/10.1016/S1726-4901(10)70081-2

[10] Navo, M.A. and Phan Vaughan, J.C. (2004) An Assessment of the Utilization of Complementary and Alternative Medication in Women with Gynecologic or Breast Malignancies. Journal of Clinical Oncology, 22, 671-677. http://dx.doi.org/10.1200/JCO.2004.04.162

[11] Liu, J.P., Yang, H., Xia, Y. and Cardini, F. (2009) Herbal Preparations for Uterine Fibroids. Cochrane Database of Systematic Reviews, No. 2, CD005292. http://dx.doi.org/10.1002/14651858.cd005292.pub2

[12] Murayama, T., Yamaguchi, N., Iwamoto, K. and Eizuru, Y. (2006) Inhibition of Ganciclovir-Resistant Human Cytomegalovirus Replication by Kampo (Japanese Herbal Medicine). Antiviral Chemistry \& Chemotherapy, 17, 11-16. http://dx.doi.org/10.1177/095632020601700102

[13] Abo, T., Kawate, T., Itoh, K. and Kumagai, K. (1981) Studies on the Bioperiodicity of the Immune Response. 1. Circadian Rhythms of Human T, B and K Cell Traffic in the Peripheral Blood. Journal of. Immunology, 126, 1360-1363.

[14] Abo, T. and Kumagai, K. (1978) Studies of Surface Immunoglobulins on Human B Lymphocytes. Physiological Variations of Sig ${ }^{+}$Cells in Peripheral Blood. Clinical Experimental Immunology, 33, 441-452.

[15] Landmann, R.M., Muller, F.B., Perini, C., Wesp, M., Erne, P. and Buhler, R. (1984) Changes of Immunoregulatory Cells Induced by Psychological and Physical Stress: Relationship to Plasma Catecholamines. Clinical Experimental Immunology, 58,127-135.

[16] Iio, A., Ohguchi, K., Naruyama, H., Tazawa, S., Araki, Y., Ichihara, K., Nozawa, Y. and Ito, M. (2012) Ethanolic Extract of Brazilian Red Propolis ABCA1 Expression and Promote Cholesterol Effulux from THP-1 Macrophage. Phytomedicine, 19, 383-388. http://dx.doi.org/10.1016/j.phymed.2011.10.007

[17] Kitada, Y., Okamoto, K., Takei, T., Jia, X.F., Chen, R., Yamaguchi, N., Tsubokawa, M., Wu, W.H., Murayama, T. and Kawakita, K. (2013) Hot Spring Hydro Therapy Regulate Peripheral Leukocyte Together with Emotional Hormone and Receptor Positive Lymphocytes According to Each Constitution/Condition. Open Journal of Rheumatology and Autoimmune Diseases, 3, 140-153. http://dx.doi.org/10.4236/ojra.2013.33022

[18] Kitada, Y., Wan, W., Matsui, K. Matsui, K., Shimizu, S. and Yamaguchi, N. (2000) Regulation of Peripheral White Blood Cells in Numbers and Functions through Hot-Spring Bathing During a Short Term-Studies in Control Experiments. Journal of Japanese Society Balneology Climatology Physiological Medicine, 63, 151-164.

[19] Jerne, N.K. and Nordin, A.A. (1963) Plaque Formation in Agar by Single Antibody Producing Cells. Science, 140,405408. http://dx.doi.org/10.1126/science.140.3565.405

[20] Jerne, N.K., Nordin, A.A. and Henry, C. (1963) The Agar Technique for Recognizing Antibody Producing Cells. In: Amons, B. and Kaprowski, H., Eds., Cell-Bound Antibodies, Wistar Institute Press, Philadelphia, 109-125.

[21] Hamada, M. and Yamaguchi, N. (1988) Effect of Kanpo Medicine, Zyuzentaihoto, on the Immune Reactivity of Tumor-Bearing Mice. Journal of Ethnopharmacology, 24, 311-320. http://dx.doi.org/10.1016/0378-8741(88)90160-2

[22] Jyumonji, N. and Fujii, Y. (1993) A New Assay for Delayed-Type Hypersensitivity in Vitro Detection F-CHLORELLA. The Macrophage Migration by Boyden Chamber. The Journal of Kanazawa Medical University, 18, 198-203.

[23] Yamaguchi, N., Shimizu, S. and Izumi, H. (2004) Hydrotherapy Can Modulate Peripheral Leukocytes: An Approach to Alternative Medicine. Advances in Experimental Medicine and Biology, 546, 239-251. http://dx.doi.org/10.1007/978-1-4757-4820-8_18

[24] Murayama, T., Yamaguchi, N., Matsuno, H. and Eizuru, Y. (2004) In Vitro Anti-Cytomegalovirus Activity of Kampo (Japanese Herbal) Medicine. Evidence-Based Complementary and Alternative Medicine, 1, 285-289.

[25] Abe, S., Yamaguchi, N., Tansho, S. and Yamaguchi, H. (2005) Preventive Effects of Juzen-taiho-to on Infectious Disease, Juzen-taiho-to (Shi-Quan-Da-Bu-Tang) Scientific Evaluation and Clinical Applications. In: Yamada, H. and Saiki, I., Eds., Traditional Herbal Medicines for Modern Times, CRC Press, Boca Raton.

[26] Nakano, S., Noguchi, T., Takekoshi, H., Suzuki, G. and Nakano, M. (2005) Maternal-Fetal Distribution and Transfer of Dioxins in Pregnant Women in Japan, and Attempts to Reduce Maternal Transfer with Chlorella (Chlorella pyrenoidosa) Supplements. Chemosphere, 61, 1244-1255. http://dx.doi.org/10.1016/j.chemosphere.2005.03.080

[27] Yamaguchi, N., Shimizu, S. and Izumi, H. (2004) Hydrotherapy Can Modulate Peripheral Leukocytes: An Approach to Alternative Medicine, Complementary and Alternative Approaches to Biomedicine. Kluwer Academic/Plenum Publishers, New York, 239-251. http://dx.doi.org/10.1007/978-1-4757-4820-8_18

[28] Shimizu, S., Kitada, H., Yokota, H., Yamakawa, J., Murayama, T., Sugiyama, K., Izumi, H. and Yamaguchi, N. (2002) 
Activation of the Alternative Complement Pathway by Agaricus blazei Murill. Phytomedicine, 9, 536-545. http://dx.doi.org/10.1078/09447110260573047

[29] Yamaguchi, N., Araai, M. and Murayama, T. (2015) Aspect of QOL Assessment and Proposed New Scale for Evaluation. Open Journal of Immunology, 4, in press.

\section{Abbreviations}

Conventional Sugarcane. Normal Sugarcane, Family Poaceae, befor fermentation.

CAM: Complementary and alternative medicine, beside the western medicine, there are many traditional medicine and/or health promoting menu all over the world.

CD: Cluster of differentiation. Each lymphocyte has name that expressed CD number, for example CD2, CD4, etc.

DM: Diabetes mellitus.

FCM: Flow Cytometry.

Fermented Sugarcane: Fermented Sugarcane by Lactobacili, abbreviate U-154 in the text.

G-rich type: The individual that exhibit over $60 \%$ of granulocyte in peripheral blood, finding many in young gentleman.

L-rich type: The individual that exhibit over $40 \%$ of lymphocyte in peripheral blood, finding lot in ladies and senile.

U-164: Fermented sugarcane, Family Poaceae, that degradated by Lactobacilli. 